\title{
Effects of consumption of main and side dishes with white rice on postprandial glucose, insulin, glucose-dependent insulinotropic polypeptide and glucagon-like peptide-1 responses in healthy Japanese men
}

\author{
Noriko Kameyama $^{1}$, Chizuko Maruyama ${ }^{1,2_{*}}$, Sadako Matsui ${ }^{2}$, Risa Araki $^{2}$, Yuichiro Yamada ${ }^{3}$ and \\ Taro Maruyama ${ }^{4}$ \\ ${ }^{1}$ Division of Food and Nutrition, Graduate School of Human Sciences and Design, Japan Women's University, \\ 2-8-1 Mejirodai, Bunkyo-ku, Tokyo 112-8681, Japan \\ ${ }^{2}$ Department of Food and Nutrition, Faculty of Human Sciences and Design, Japan Women's University, 2-8-1 Mejirodai, \\ Bunkyo-ku, Tokyo 112-8681, Japan \\ ${ }^{3}$ Department of Endocrinology, Diabetes and Geriatric Medicine, Akita University Graduate School of Medicine, \\ 1-1-1 Hondo, Akita City, Akita 010-8543, Japan \\ ${ }^{4}$ Department of Internal Medicine, Saitama Social Insurance Hospital, 4-9-3 Kitaurawa, Urawa-ku, Saitama City, \\ Saitama 330-0074, Japan
}

(Submitted 16 July 2013 - Final revision received 27 November 2013 - Accepted 28 November 2013 - First published online 10 February 2014)

\begin{abstract}
The co-ingestion of protein, fat and fibre with carbohydrate reportedly affects postprandial glucose, insulin and incretin (glucose-dependent insulinotropic polypeptide (GIP) and glucagon-like peptide-1 (GLP-1)) responses. However, the effects of combination dishes with carbohydrate-rich foods at typically eaten amounts remain unclear. The objective of the present study was to evaluate the effects of consuming recommended amounts of side dishes with boiled white rice in the same meal on postprandial plasma glucose, insulin and incretin hormone responses. A total of nine healthy male volunteers consumed four different meals in a random order on separate days. The test meals were as follows: S, white rice; SM, addition of protein-rich main dishes to the S meal; SMF, addition of a fat-rich food item to the SM meal; SMFV, addition of vegetables to the SMF meal. Plasma glucose, GIP and GLP-1 and serum insulin concentrations were determined during a $3 \mathrm{~h}$ period after consumption of these meals. Postprandial glucose responses were lower after SMFV meal consumption than after consumption of the other meals. The incremental AUC for GIP (0-180 min) were largest after consumption of the SMF and SMFV meals, followed by that after SM meal consumption, and was smallest after $S$ meal consumption $(P<0 \cdot 05)$. Furthermore, we found GIP concentrations to be dose dependently increased by the fat content of meals of ordinary size, despite the amount of additional fat being small. In conclusion, the combination of recommended amounts of main and vegetable side dishes with boiled white rice is beneficial for lowering postprandial glucose concentrations, with an increased incretin response, when compared with white rice alone.
\end{abstract}

Key words: Postprandial responses: Glucose: Incretins: Vegetable intake

Fasting plasma glucose concentrations must be lowered to control fasting hyperglycaemia, but decreasing postprandial plasma glucose concentrations, i.e. control of postprandial hyperglycaemia, is also important for achieving glycosylated haemoglobin $(\mathrm{HbA} 1 \mathrm{c})$ targets $^{(1-3)}$. In addition, reduction of postprandial hyperglycaemia is also desirable as it is an independent risk factor for macrovascular disease in people with diabetes $^{(1,4)}$. Thus, the importance of lowering postprandial plasma glucose concentrations as a therapeutic target in diabetes has been recognised ${ }^{(1)}$.
Postprandial plasma glucose concentrations are well known to be determined mainly by the amount and type of carbohydrate present in a meal ${ }^{(5)}$. Recently, the effects of nutrients on incretin secretion have attracted research attention. Among the incretin hormones, glucose-dependent insulinotropic polypeptide (GIP) and glucagon-like peptide-1 (GLP-1), both released from the gut, stimulate insulin secretion in a glucose-dependent manner ${ }^{(6,7)}$. The secretion of both GIP and GLP-1 is enhanced in response to the ingestion of meals or glucose ${ }^{(6,8)}$. Furthermore, co-ingestion of protein, fat

Abbreviations: GIP, glucose-dependent insulinotropic polypeptide; GLP-1, glucagon-like peptide-1; IAUC, incremental AUC; S, staple food; SM, staple food and main dish; SMF, staple food, main dish and fat-rich food item; SMFV, staple food, main dish, fat-rich food item and vegetable dish. 
and fibre with carbohydrate reportedly affects postprandial glucose, insulin, GIP and GLP-1 responses ${ }^{(5,9,10)}$. Therefore, differences among various nutrient combinations with carbohydrate have been suggested to affect postprandial glucose and incretin responses.

With regard to meal planning, Japanese patients with diabetes have been educated to prepare three dishes: one serving as their staple food, a main dish and a vegetable dish called, respectively, 'shushoku', 'shusai' and 'fukusai' to be eaten in one meal ${ }^{(11)}$. Because Japanese commonly consume carbohydrate from 'shushoku' consisting of grains, typically boiled white rice, the amount of 'shushoku' should be the major determinant of the postprandial glucose response. On the other hand, main dishes called 'shusai', prepared with meat, poultry, fish, egg and soyabean products, such as tofu, are rich in protein, while the 'fukusai' side dishes prepared with vegetables provide various vitamins, minerals and dietary fibre. These dishes can be cooked with or without oil. Therefore, combination meals comprising these three types of dishes have long been considered to be nutritionally well balanced ${ }^{(12)}$.

Recently, the effects of side dishes rich in protein and fat ${ }^{(13)}$ or rich in viscous fibre ${ }^{(14)}$ on lowering of the postprandial glucose response have been reported. However, no study has examined incretin responses or evaluated the differences among combination types of meals with stepwise additions of side dishes to carbohydrate-rich foods in amounts typically eaten by Japanese people.

Therefore, in the present study, we assessed the effects of consuming shusai (main dish) and/or fukusai (vegetable side dishes) with boiled white rice (shushoku) in the same meal on postprandial glucose, insulin, GIP and GLP-1 responses in healthy Japanese men to obtain preliminary information on postprandial glucose and incretin responses to clarify the mechanism by which dietary therapy works in patients with diabetes.

\section{Subjects and methods}

\section{Subjects}

The necessary sample size, calculated by referring to blood glucose data from a prior study, using 0.05 for the $\alpha$-error and 0.20 for the $\beta$-error, was seven subjects. The subjects were recruited via e-mail. Inclusion criteria were male sex, age between 30 and 49 years, and a BMI between 18.5 and $25 \mathrm{~kg} / \mathrm{m}^{2}$. Baseline data on health and lifestyle including habitual food intake were collected using questionnaires. Subjects were excluded if a disease and/or glucose metabolism abnormalities had been detected at their most recent medical check-up or they had a family history of endocrine and/or metabolic disease. A total of nine healthy Japanese men volunteered to participate in the present study at Japan Women's University, Tokyo, Japan.

The present study was conducted according to the guidelines laid down in the Declaration of Helsinki, and all procedures involving human subjects were approved by the ethics committee of Japan Women's University (No. 48). Written informed consent was obtained from all subjects.

\section{Test meals}

In the present study, four test meals were designed using boiled white rice as a staple food, with or without side dishes (Table 1). The test meals were as follows: staple food alone (S) as a control meal; staple food and main dish (SM) as a model of a meal with a low-fat main dish; staple food, main dish and fat-rich food item (SMF) as a model of a meal containing a recommended amount of fat; staple food, main dish, fat-rich food item and vegetable dish (SMFV) as a model of a meal containing vegetables along with the other three components. Boiled white rice weighing $200 \mathrm{~g}$ (aseptic packed Sato Rice; Sato Foods Company Limited) heated in a microwave oven for $2 \mathrm{~min}$ served as the staple food. Main dishes consisted of an egg boiled for $10 \mathrm{~min}$ in water and tofu (soyabean curd) (momen-tofu; Takanofoods Company Limited). Mayonnaise (Kewpie Corporation) was used as the fat-rich food item. Vegetable dishes consisted of boiled spinach and boiled broccoli. Frozen spinach (Kewpie Corporation) was boiled for $1 \mathrm{~min}$ in water, soaked in cold water for $2 \mathrm{~min}$, squeezed dry and then cut into pieces of $1 \mathrm{~cm}$ length. Frozen broccoli (Kewpie Corporation) was boiled for $1 \mathrm{~min}$ in water. Each test meal was seasoned with $3 \mathrm{~g}$ of soya sauce (Kikkoman Corporation) and served with $200 \mathrm{ml}$ of hot water. All test meals were prepared just before the study. The detailed composition and calculated energy and nutrient contents of the test meals, based on standard tables

Table 1. Composition and nutrient and energy contents of the four test meals

\begin{tabular}{|c|c|c|c|c|}
\hline \multirow[b]{2}{*}{ Dishes and foods } & \multicolumn{4}{|c|}{ Test meals } \\
\hline & S & SM & SMF & SMFV \\
\hline \multicolumn{5}{|l|}{ Staple food } \\
\hline Boiled white rice $(\mathrm{g})^{*}$ & 200 & 200 & 200 & 200 \\
\hline \multicolumn{5}{|l|}{ Main dish } \\
\hline Tofu (soyabean curd) (g) $†$ & - & 100 & 100 & 100 \\
\hline Boiled egg (g) & - & 50 & 50 & 50 \\
\hline \multicolumn{5}{|l|}{ Fat-rich food item } \\
\hline Mayonnaise $(\mathrm{g}) \ddagger$ & - & - & 13 & 13 \\
\hline \multicolumn{5}{|l|}{ Vegetable dish } \\
\hline Boiled spinach (g)‡ & - & - & - & 60 \\
\hline Boiled broccoli (g)‡ & - & - & - & 60 \\
\hline \multicolumn{5}{|l|}{ Seasoning } \\
\hline Soya sauce $(\mathrm{g}) \S$ & 3 & 3 & 3 & 3 \\
\hline \multicolumn{5}{|l|}{ Drink } \\
\hline Hot water (ml) & 200 & 200 & 200 & 200 \\
\hline \multicolumn{5}{|l|}{ Energy and nutrients } \\
\hline Energy (kJ) & 1414 & 2033 & 2397 & 2527 \\
\hline Energy (kcal) & 338 & 486 & 573 & 604 \\
\hline Protein $(\mathrm{g})$ & $5 \cdot 2$ & $18 \cdot 3$ & $18 \cdot 6$ & $22 \cdot 3$ \\
\hline Fat $(\mathrm{g})$ & 0.6 & $9 \cdot 8$ & $19 \cdot 2$ & $19 \cdot 7$ \\
\hline Carbohydrate (g) & 73.9 & $75 \cdot 3$ & 75.5 & $76 \cdot 1$ \\
\hline Total dietary fibre $(\mathrm{g})$ & 0.6 & 1.0 & 1.0 & 5.4 \\
\hline Soluble dietary fibre $(\mathrm{g})$ & 0.0 & 0.1 & 0.1 & 1.0 \\
\hline Insoluble dietary fibre (g) & 0.6 & 0.9 & 0.9 & 4.4 \\
\hline
\end{tabular}

S, staple food; SM, staple food and main dish; SMF, staple food, main dish and fat-rich food item; SMFV, staple food, main dish, fat-rich food item and vegetable dish.

${ }^{*}$ Aseptic packed Sato Rice; Sato Foods Company Limited.

† Momen-tofu; Takanofoods Company Limited.

$\ddagger$ Kewpie Corporation.

$\S$ Kikkoman Corporation. 
of food components in Japan (5th edition), are given in Table 1. The SMFV meal conformed to the recommended standard meals for Japanese ${ }^{(15)}$.

\section{Protocol}

The present study was conducted using a randomised, singleblind, cross-over design. All subjects consumed each type of meal, and the duration of the washout period was at least 1 week. Randomisation of the order of consuming each test meal was generated individually using random numbers. While the subjects and staff members who served the test meals were aware of the consumed test meal, data analysts and assessors were blinded to the order of test meal consumption.

The subjects were instructed to maintain their habitual diet and physical activity patterns during the study period and to record data on their daily meals, health status and physical activity. The subjects recorded data on their food intake in detail in $24 \mathrm{~h}$ food diaries the day before each test day. They were instructed to finish consuming the same dishes before 21.00 hours the day before each of the test days, ensuring that they fasted overnight.

On the morning of the test, the subjects arrived at Japan Women's University by 09.00 hours. Anthropometric measurements and fasting blood collection were conducted after the aforementioned overnight fast. Immediately after providing a fasting blood sample, the subjects began consuming the test meal. To exclude any influence of the order of meal consumption, the subjects were instructed to eat the boiled white rice and side dishes alternately, to masticate each mouthful of food twenty times before swallowing and to finish eating the entire amount of food in just $15 \mathrm{~min}$. The test meals were consumed under supervision. Venous blood samples were drawn by venepuncture before and 30, 60, 120 and $180 \mathrm{~min}$ after meal ingestion. The subjects remained seated throughout the test under the supervision of research staff members.

\section{Measurements}

Height, weight and waist circumference of the subjects were measured. Visceral fat area was measured employing the dual impedance analysis method using HDS-2000 DUALSCAN (Omron Healthcare Company Limited).

Plasma glucose, serum insulin, plasma total GIP and plasma intact GLP-1 concentrations were measured at all time points. HbA1c concentration was measured only during the first visit.

At all time points, blood was collected into three tubes: one for serum separation; another for plasma glucose analysis (containing sodium fluoride and potassium oxalate); the last one for plasma incretin analysis. For plasma incretin analysis, to prevent the degradation of intact GIP and intact GLP-1 by dipeptidyl peptidase-4, blood samples were collected directly into BD P800 Blood Collection Tubes (Becton Dickinson) containing a dipeptidyl peptidase- 4 inhibitor. The tubes were kept on ice until centrifugation. Blood samples were immediately centrifuged, and samples of the separated plasma and serum were stored at $-80^{\circ} \mathrm{C}$ until analysis.
Plasma glucose concentration was measured with the hexokinase UV method, HbA1c concentration was measured employing HPLC, and serum total cholesterol, LDLcholesterol, HDL-cholesterol and TAG concentrations were measured using enzymatic methods in the laboratory at Saitama Social Insurance Hospital, Saitama, Japan. Serum insulin concentration was measured using RIA at Bio Medical Laboratories, Inc., Tokyo, Japan.

Total GIP concentration was measured using the Human GIP (total) ELISA Kit (Millipore Corporation) according to the manufacturer's instructions. The kit recognises both isoforms of GIP (GIP 1-42 and 3-42) at a cross-reactivity of $100 \%$ and the detection limit is $1.6 \mathrm{pmol} / 1$. The intra-assay and inter-assay $\mathrm{CV}$ are $<8.8$ and $<6.1 \%$, respectively.

Intact GLP-1 concentration was measured using Glucagon Like Peptide-1 (Active) ELISA (Millipore Corporation) after solid-phase extraction of plasma using Oasis HLB extraction plates at $30 \mathrm{mg} /$ ninety-six wells (Waters Corporation) in Mitsubishi Chemical Medience Corporation, Tokyo, Japan. The kit recognises GLP-1 isoforms at the following cross-reactivities: GLP-1 (1-37) - 0.2\%; GLP-1 (7-37) - 99.5\%; GLP-1 (9-37) - not detected; GLP-1 (1-36) amide - 0.2\%; GLP-1 (7-36) amide - 100\%; GLP-1 (9-36) amide - not detected. The detection limit is $0.83 \mathrm{pmol} / 1$, and the intra-assay and interassay $\mathrm{CV}$ are $<14.9$ and $<13.2 \%$, respectively.

\section{Calculations and statistical analyses}

BMI was calculated employing the following formula: BMI = weight $(\mathrm{kg}) /$ height $(\mathrm{m})^{2}$. Incremental AUC (IAUC), ignoring the areas below the baseline, for glucose, insulin, GIP and GLP-1 were calculated using the trapezoidal rule.

Statistical analyses were carried out using SPSS for Windows (version 16.0J; SPSS Japan, Inc.). All values are reported as means with their standard errors. The statistical significance of differences in values obtained after fasting and consumption of each test meal were assessed using the non-parametric Friedman test followed by the Wilcoxon signed-ranks test for pairwise comparisons with Bonferroni's correction. The carry-over and period effect was evaluated using the nonparametric Friedman test. $P<0.05$ was considered to be statistically significant.

\section{Results}

All subjects completed the study and consumed all test meals, entirely, without problems. No adverse events such as abdominal pain and diarrhoea were observed during the study period.

The subjects were 38.1 (SEM 1.8) years of age with BMI of $23 \cdot 1$ (SEM 0.5$) \mathrm{kg} / \mathrm{m}^{2}$, waist circumference of $81 \cdot 1$ (SEM 1.4$) \mathrm{cm}$, visceral fat area of $54.9(\mathrm{SEM} 6.1) \mathrm{cm}^{2}$, HbA1c concentration of $5 \cdot 3$ (SEM $0 \cdot 1$ ) \% and normal serum lipidaemic parameters. Body weights did not change during the study period, and there were no significant differences in fasting biochemical parameters just before consumption of the four test meals (Table 2) and no carry-over and period effect was observed. 
Table 2. Body weight and fasting values of plasma glucose, serum insulin, plasma total glucose-dependent insulinotropic polypeptide (GIP) and plasma intact glucagon-like peptide-1 (GLP-1) in healthy men before consumption of the four test meals containing the same amount of boiled white rice with or without side dishes*

(Mean values with their standard errors, $n$ 9)

\begin{tabular}{|c|c|c|c|c|c|c|c|c|}
\hline & \multicolumn{8}{|c|}{ Test meals } \\
\hline & \multicolumn{2}{|c|}{$S$} & \multicolumn{2}{|c|}{ SM } & \multicolumn{2}{|c|}{ SMF } & \multicolumn{2}{|c|}{ SMFV } \\
\hline & Mean & SEM & Mean & SEM & Mean & SEM & Mean & SEM \\
\hline Body weight (kg) & $67 \cdot 2$ & 0.9 & $67 \cdot 0$ & 1.0 & $66 \cdot 9$ & $1 \cdot 1$ & $67 \cdot 0$ & 0.9 \\
\hline Plasma glucose $(\mathrm{mmol} / \mathrm{l})$ & $5 \cdot 37$ & 0.12 & $5 \cdot 38$ & 0.16 & $5 \cdot 19$ & 0.14 & $5 \cdot 30$ & 0.15 \\
\hline Insulin $(\mu \mathrm{U} / \mathrm{ml}) \dagger$ & 6 & 1 & 6 & 1 & 7 & 1 & 6 & 1 \\
\hline GIP (pmol/l) & 15 & 3 & 13 & 2 & 16 & 3 & 14 & 3 \\
\hline GLP-1 (pmol/l) & 1.34 & 0.12 & 1.30 & 0.12 & 1.25 & $0 \cdot 12$ & 1.30 & 0.18 \\
\hline
\end{tabular}

S, staple food; SM, staple food and main dish; SMF, staple food, main dish and fat-rich food item; SMFV, staple food, main dish, fat-rich food item and vegetable dish.

${ }^{*}$ Differences in values obtained just before consumption of the four test meal values were not statistically significant

(Wilcoxon signed-ranks test with Bonferroni's correction).

$\dagger 1 \mu \mathrm{U} / \mathrm{ml}=6.0 \mathrm{pmol} / \mathrm{l}$.

\section{Plasma glucose responses}

The postprandial responses and the IAUC of plasma glucose after consumption of each meal are shown in Fig. 1 and Table 3.

Plasma glucose concentrations peaked at $30 \mathrm{~min}$ after consumption of all four test meals. At $30 \mathrm{~min}$, the change in plasma glucose concentrations after SMFV meal consumption tended to be lower than that after $S$ meal consumption $(P=0.077)$ and was significantly lower than that after SM meal consumption $(P=0 \cdot 046)$. Thereafter, the change in plasma glucose concentrations after SMFV meal consumption remained low when compared with that after consumption of other test meals at $60 \mathrm{~min}$ and was significantly lower than that after SMF meal consumption at $120 \mathrm{~min}(P=0.045)$.

IAUC for plasma glucose after SMFV meal consumption tended to be smaller at $0-30 \mathrm{~min}(P=0.078)$ and $0-60 \mathrm{~min}$ $(P=0 \cdot 090)$, being significantly smaller at $0-120 \mathrm{~min}(P=0.046)$, than those after $S$ meal consumption. In addition, IAUC for plasma glucose after SMFV meal consumption were also significantly smaller than those after SM meal consumption at $0-30 \mathrm{~min}$ and $0-60 \mathrm{~min}$ (both $P=0.046$ ). At $0-180 \mathrm{~min}$, the percentages of mean IAUC for plasma glucose after consumption of the SM, SMF and SMFV meals, against that after S meal consumption, were 87,94 and $63 \%$, respectively.

\section{Serum insulin responses}

No significant differences were observed in the increases in postprandial responses or the IAUC for serum insulin after consumption of the four test meals (Fig. 2 and Table 3).

\section{Plasma total glucose-dependent insulinotropic polypeptide responses}

Postprandial plasma total GIP concentrations increased significantly after consumption of all four test meals when compared with those in the fasting state (Fig. 3). GIP concentrations peaked at $30 \mathrm{~min}$ after $\mathrm{S}$ meal consumption, but not until 60 min after consumption of the SM, SMF and SMFV meals.
GIP concentrations gradually decreased with time, but were still higher than those in the fasting state even $180 \mathrm{~min}$ after meal consumption.

Changes in GIP concentrations after consumption of the SM, SMF and SMFV meals were larger than those after $S$ meal consumption at all measurement time points $(P=0 \cdot 046$, respectively). Furthermore, changes in GIP concentrations after SMF meal consumption were larger than those after SM meal consumption at $30 \mathrm{~min}$ and $60 \mathrm{~min}(P=0 \cdot 046$, respectively).

IAUC for GIP after consumption of the SM, SMF and SMFV meals were larger than those after $S$ meal consumption, and those after SMF meal consumption were larger than those after SM meal consumption at all measurement time points $(P=0 \cdot 046$, respectively) (Table 3$)$. Furthermore, IAUC for GIP after SMFV meal consumption was larger than that after

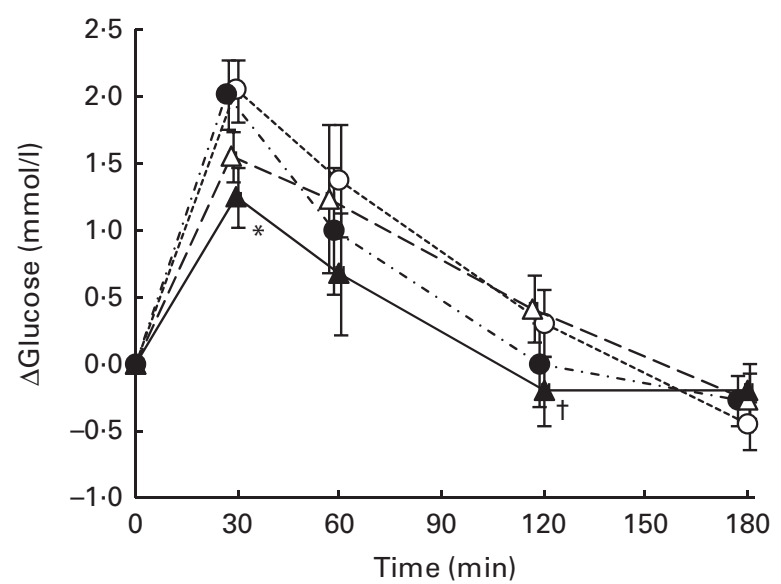

Fig. 1. Mean postprandial changes $(\Delta)$ in plasma glucose concentrations in healthy men during a 180 min period after consumption of four test meals containing the same amount of boiled white rice with or without side dishes: S meal, staple food (-....); SM meal, staple food and main dish (-...); SMF

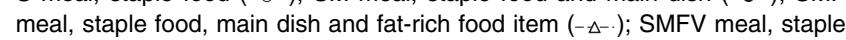
food, main dish, fat-rich food item and vegetable dish $\left(\_\right)$. Values are means, with their standard errors represented by vertical bars $(n 9)$. * Mean values were significantly different from those obtained after SM meal consumption $(P<0.05)$. † Mean values were significantly different from those obtained after SMF meal consumption $(P<0.05$; Wilcoxon signed-ranks test with Bonferroni's correction). 
Table 3. Incremental AUC for plasma glucose, serum insulin, plasma total glucose-dependent insulinotropic polypeptide (GIP) and plasma intact glucagon-like peptide-1 (GLP-1) in healthy men after consumption of the four test meals containing the same amount of boiled white rice with or without side dishes

(Mean values with their standard errors, $n$ 9)

\begin{tabular}{|c|c|c|c|c|c|c|c|c|}
\hline & \multicolumn{8}{|c|}{ Test meals } \\
\hline & \multicolumn{2}{|c|}{$S$} & \multicolumn{2}{|c|}{ SM } & \multicolumn{2}{|c|}{ SMF } & \multicolumn{2}{|c|}{ SMFV } \\
\hline & Mean & SEM & Mean & SEM & Mean & SEM & Mean & SEM \\
\hline \multicolumn{9}{|c|}{ Plasma glucose $(\mathrm{mmol} \times \mathrm{min} / \mathrm{l})$} \\
\hline $0-30 \mathrm{~min}$ & 31 & 3 & 30 & 4 & 23 & 3 & $19 \dagger$ & 3 \\
\hline $0-60 \min$ & 82 & 11 & 76 & 13 & 66 & 11 & $51 \dagger$ & 11 \\
\hline $0-120 \mathrm{~min}$ & 135 & 25 & 117 & 31 & 123 & 30 & $83^{*}$ & 22 \\
\hline $0-180 \mathrm{~min}$ & 148 & 27 & 129 & 39 & 139 & 37 & 93 & 28 \\
\hline \multicolumn{9}{|c|}{ Insulin $(\mu \mathrm{U} \times \min / \mathrm{ml}) \ddagger$} \\
\hline $0-30 \mathrm{~min}$ & 712 & 136 & 925 & 158 & 983 & 249 & 792 & 116 \\
\hline $0-60 \min$ & 1962 & 298 & 2692 & 433 & 2898 & 617 & 2395 & 311 \\
\hline $0-120 \mathrm{~min}$ & 3958 & 476 & 5198 & 795 & 5725 & 1009 & 4705 & 651 \\
\hline $0-180 \mathrm{~min}$ & 5075 & 638 & 6498 & 1010 & 7038 & 1180 & 5978 & 802 \\
\hline \multicolumn{9}{|c|}{ GIP $(\mathrm{pmol} \times \min / \mathrm{l})$} \\
\hline $0-30 \mathrm{~min}$ & 614 & 98 & $932^{*}$ & 98 & $1345^{*} \dagger$ & 156 & $1130^{*}$ & 190 \\
\hline $0-60 \mathrm{~min}$ & 1798 & 250 & 2919* & 315 & $4367^{*} \dagger$ & 530 & $3625^{\star}$ & 469 \\
\hline $0-120 \mathrm{~min}$ & 3970 & 498 & $6859^{*}$ & 731 & $10381^{*} \dagger$ & 1276 & $8759^{*}$ & 821 \\
\hline $0-180 \mathrm{~min}$ & 5591 & 709 & 9969* & 1004 & $14847^{*} \dagger$ & 1598 & $13041^{*} \dagger$ & 1068 \\
\hline \multicolumn{9}{|c|}{ GLP-1 $(\mathrm{pmol} \times \mathrm{min} / \mathrm{l})$} \\
\hline $0-30 \mathrm{~min}$ & 34 & 6 & 44 & 11 & 35 & 4 & 57 & 13 \\
\hline $0-60 \min$ & 87 & 13 & 114 & 24 & 102 & 11 & 141 & 26 \\
\hline $0-120 \mathrm{~min}$ & 178 & 25 & 221 & 35 & 258 & 24 & 268 & 32 \\
\hline $0-180 \mathrm{~min}$ & 262 & 42 & 315 & 46 & 407 & 36 & 389 & 49 \\
\hline
\end{tabular}

S, staple food; SM, staple food and main dish; SMF, staple food, main dish and fat-rich food item; SMFV, staple food, main dish, fat-rich food item and vegetable dish.

* Mean values were significantly different from those obtained after $S$ meal consumption $(P<0.05$; Wilcoxon signed-ranks test with Bonferroni's correction).

† Mean values were significantly different from those obtained after SM meal consumption $(P<0.05$; Wilcoxon signed-ranks test with Bonferroni's correction)

$\ddagger 1 \mu \mathrm{U} / \mathrm{ml}=6.0 \mathrm{pmol} / \mathrm{l}$.

SM meal consumption at $0-180 \mathrm{~min}(P=0 \cdot 046)$. No significant difference was observed after consumption of the SMF and SMFV meals. At 0-180 min, the percentages of mean IAUC for GIP after consumption of the SM, SMF and SMFV meals, against that after $S$ meal consumption, were 178, 226 and $233 \%$, respectively.

\section{Plasma intact glucagon-like peptide-1 responses}

Postprandial plasma intact GLP-1 concentrations increased significantly after consumption of all four test meals when compared with those in the fasting state (Fig. 4). GLP-1 concentrations peaked at $30 \mathrm{~min}$ after consumption of the $\mathrm{S}$, SM and SMFV meals, but peaked at $120 \mathrm{~min}$ after SMF meal consumption. At $120 \mathrm{~min}$, changes in GLP-1 concentrations after SMF meal consumption tended to be larger than those after consumption of the $\mathrm{S}(P=0.065)$ and $\mathrm{SM}(P=0.091)$ meals. However, differences in IAUC for GLP-1 did not reach statistical significance (Table 3).

\section{Discussion}

The co-ingestion of main dishes with white rice suppressed the postprandial glucose response when compared with the ingestion of white rice alone, despite the low-fat main dish and the moderate-fat main dish having extra energy contents of $619 \mathrm{~kJ}(148 \mathrm{kcal})$ and $983 \mathrm{~kJ}(235 \mathrm{kcal})$, respectively.
Furthermore, addition of vegetable side dishes to a meal with a moderate-fat main dish may decrease the postprandial glucose response without excessively increasing insulin and GIP responses, when compared with meals consisting of only white rice and a main dish.

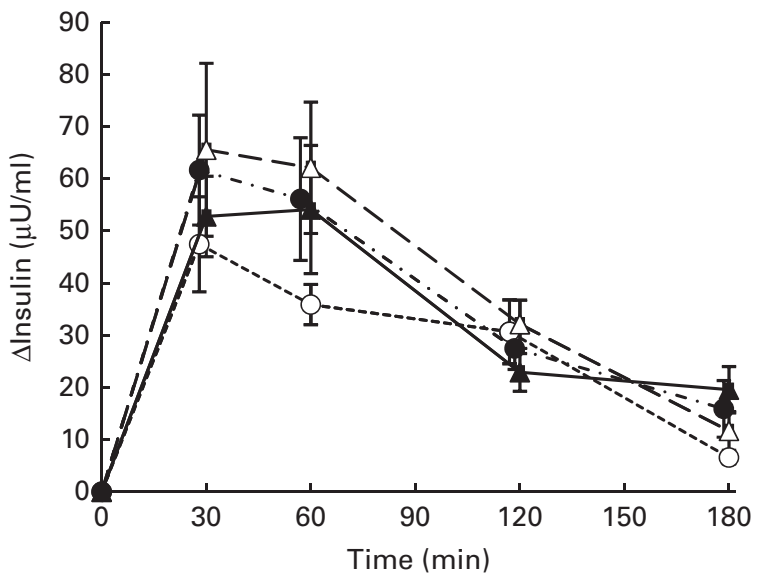

Fig. 2. Mean postprandial changes $(\Delta)$ in serum insulin concentrations in healthy men during a $180 \mathrm{~min}$ period after consumption of four test meals containing the same amount of boiled white rice with or without side dishes: S meal, staple food (--o-.); SM meal, staple food and main dish (- •-.); SMF meal, staple food, main dish and fat-rich food item (-॰-); SMFV meal, staple food, main dish, fat-rich food item and vegetable dish $(\leftarrow-)$. Values are means, with their standard errors represented by vertical bars $(n 9)$. For insulin, $1 \mu \mathrm{U} / \mathrm{ml}=6.0 \mathrm{pmol} / \mathrm{l}$. 


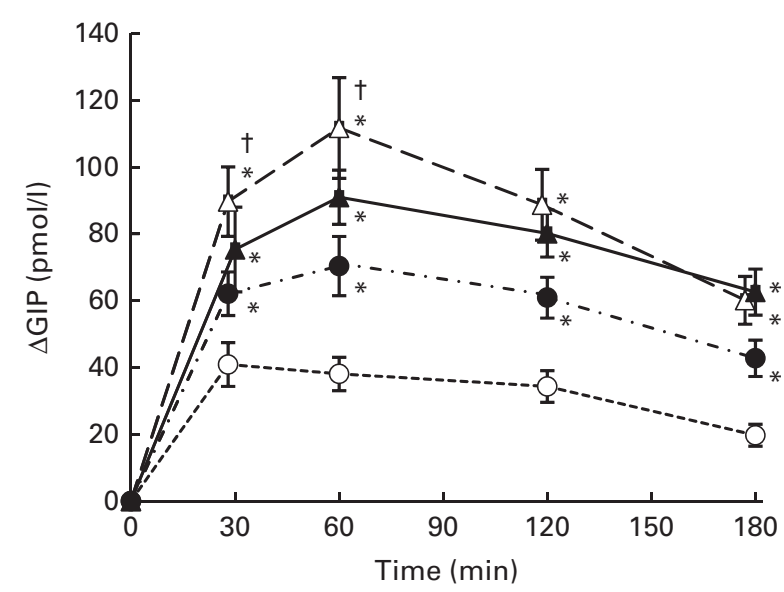

Fig. 3. Mean postprandial changes $(\Delta)$ in plasma total glucose-dependent insulinotropic polypeptide (GIP) concentrations in healthy men during a $180 \mathrm{~min}$ period after consumption of four test meals containing the same amount of boiled white rice with or without side dishes: $\mathrm{S}$ meal, staple food (-....); SM meal, staple food and main dish (-. - -); SMF meal, staple food, main dish and fat-rich food item (- $\left.\Delta_{-}\right)$; SMFV meal, staple food, main dish, fat-rich food item and vegetable dish $(\rightarrow-)$. Values are means, with their standard errors represented by vertical bars $(n 9)$. ${ }^{*}$ Mean values were significantly different from those obtained after $S$ meal consumption $(P<0.05)$. † Mean values were significantly different from those obtained after SM meal consumption $(P<0.05$; Wilcoxon signed-ranks test with Bonferroni's correction).

In the present study, consumption of boiled egg and tofu with white rice led to almost the same change in postprandial glucose concentrations, without a statistically significant increase in postprandial insulin concentrations, similar to the ingestion of white rice alone. Several studies have revealed that co-ingestion of protein in amounts of $60 \%$, or even more, relative to the amount of carbohydrate decreases the postprandial plasma glucose response concurrently with an increase in serum insulin concentrations when compared with the ingestion of carbohydrate-rich food alone $e^{(13,16,17)}$. The small protein amount $(13.1 \mathrm{~g}, 17 \%$ to carbohydrate) may explain the lack of differences in postprandial glucose and insulin responses after consumption of the SM and S meals in the present study.

In earlier studies, the mechanisms underlying elevated insulin concentrations after co-ingestion of protein-rich foods were speculated to involve a direct effect of the ingested amino acids on $\beta$-cells or incretin. Nilsson et al. ${ }^{(18)}$ reported wheyinduced insulin secretion, which might occur not only via incretins but also due to increments in the concentrations of specific plasma amino acids. However, it has been pointed out that plasma amino acid responses after ingestion of the intact protein are lower in general than those after ingestion of amino acids or the protein hydrolysates ${ }^{(19)}$. Furthermore, after consumption of protein-rich foods, the increase in the concentrations of amino acids in the circulation occurs reportedly later than the insulin response ${ }^{(16)}$, and the mean gastric halfemptying time for egg protein has been reported to be $90 \min ^{(20)}$. From these results, we speculate that the absorption of boiled egg and tofu would not provide enough amino acids to have influenced insulin secretion in the present study.
Earlier studies ${ }^{(13,16,17)}$ focusing on protein-rich foods consumed on a daily basis did not measure incretin concentrations. While an effect of ingested purified protein on postprandial GIP release and insulin secretion has been reported, the results differed for GLP-1 responses ${ }^{(18,21,22)}$. The observed increase in the total GIP response after consumption of a main dish of recommended size was assumed to have contributed to elevating postprandial insulin concentrations in the present study. However, no association was observed between GIP and insulin concentrations. Carrel et $a{ }^{(23)}$ documented that the fat, but not the protein, content of a mixed nutrient meal elicited a significant incretin effect. As the egg and tofu that we used for the main dish in the present study contained not only protein but also $9.2 \mathrm{~g}$ of fat, fat in the SM meal may have contributed to the postprandial glucose and incretin responses.

The consumption of high-fat foods (27.7-100 g) with carbohydrate-rich food (50 or $75 \mathrm{~g}$ of carbohydrate) has been reported to reduce the postprandial glucose response with no effect on the insulin response $\mathrm{e}^{(24-27)}$. However, most of these studies have demonstrated the concentrations of both plasma GIP and GLP-1 to increase after ingestion of high-fat foods with carbohydrate-rich food ${ }^{(24-26)}$. To clarify the effect of additional fat in realistic amounts in a mixed meal, we added $9.4 \mathrm{~g}$ of fat to the SM meal; i.e. the SMF meal contained a total of $19 \cdot 2 \mathrm{~g}$ of fat to approximately $75 \mathrm{~g}$ of carbohydrate. The small amount of added fat did not significantly decrease the postprandial glucose response or increase the postprandial insulin response, when compared with either the SM or the $S$ meal. However, a remarkable increase in postprandial total GIP concentrations was observed. It is worth noting that postprandial total GIP concentrations were associated with a commensurate increase in the fat content of the meals, i.e. $0 \cdot 6,9 \cdot 8$ and $19 \cdot 2 \mathrm{~g}$ in the S, SM and SMF meals, respectively. In an animal study, increasing the infusion of lipid has been

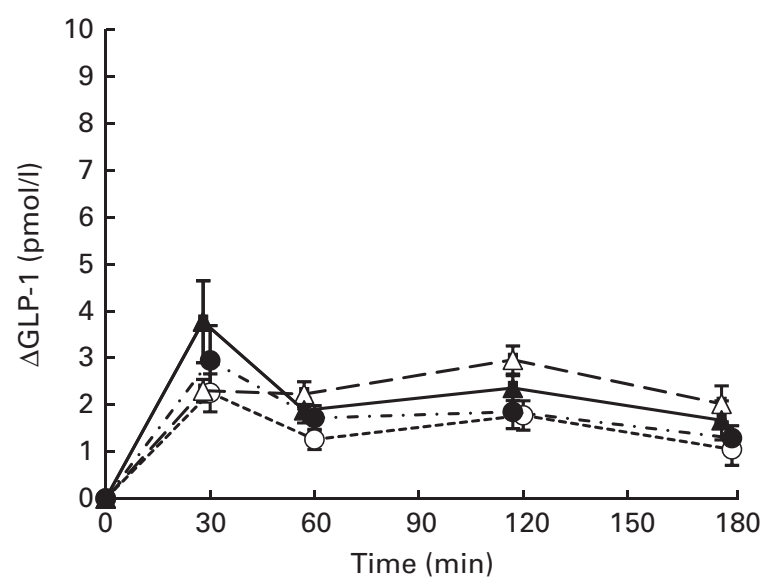

Fig. 4. Mean postprandial changes $(\Delta)$ in plasma intact glucagon-like peptide-1 (GLP-1) concentrations in healthy men during a $180 \mathrm{~min}$ period after consumption of four test meals containing the same amount of boiled white rice with or without side dishes: S meal, staple food (-..-.); SM meal, staple food and main dish (-.-); SMF meal, staple food, main dish and fat-rich food item $\left(--_{-}\right)$; SMFV meal, staple food, main dish, fat-rich food item and vegetable dish $\left(\_\right)$. Values are means, with their standard errors represented by vertical bars $(n 9)$. 
found to result in dose-dependent secretion of total GIP and intact GLP-1 into lymph ${ }^{(28)}$. In the present study, despite the amount of additional fat being small, we found total GIP concentrations to be dose dependently increased in healthy subjects consuming meals of ordinary size.

In contrast to the GIP response, the intact GLP-1 response did not change significantly in response to the addition of fat in the present study, as was the case in prior studies ${ }^{(8,23,29)}$. It has been suggested that differences in fatty acid compositions $^{(26,30)}$ are associated with changes in GLP-1 secretion, and types of proteins and amino acid compositions have also attracted attention for their roles in GLP-1 secretion ${ }^{(18,31)}$ However, Lan-Pidhainy \& Wolever ${ }^{(21)}$ confirmed that postprandial intact GLP-1 concentrations do not increase with ingestion of a small amount of fat or a small amount of protein. One reason for the lack of a significant difference in GLP-1 responses reported herein is probably the smaller amount of fat and protein used in the present study compared with that used in earlier studies ${ }^{(21,22,24-26)}$

The present results suggest that combining realistically sized shusai (main dishes) containing an optimal amount of protein and fat with white rice exerts a favourable effect on postprandial glucose responses despite the increased energy intake. Furthermore, the SMFV meal lowered the postprandial glucose response more than the meals without vegetables in the present study. Dietary fibre in the vegetable dish is probably another factor related to the inhibition of glucose absorption in the intestine. Soluble dietary fibre has been regarded as the meal component most likely to be therapeutically useful for modifying postprandial hyperglycaemia ${ }^{(10,32)}$. However, very large amounts of fibre ( $10 \mathrm{~g}$ or more) were added to meals in studies in which postprandial glucose responses were found to be markedly reduced ${ }^{(33-35)}$

Many studies have focused on purified dietary fibre or fibre in grain products, and a few studies have focused on the effects of adding vegetables to carbohydrate-rich foods or a mixed meal on postprandial glucose responses ${ }^{(13,36)}$. Gustafsson et al. ${ }^{(36)}$ reported a decreased postprandial glucose response with the addition of $250 \mathrm{~g}$ of spinach containing $7 \cdot 2 \mathrm{~g}$ of total dietary fibre to a mixed meal containing $59 \mathrm{~g}$ of carbohydrate. However, in the present study, the addition of a $120 \mathrm{~g}$ vegetable dish containing $4.4 \mathrm{~g}$ of total dietary fibre and $0.9 \mathrm{~g}$ of soluble dietary fibre to the meal consisting of approximately $75 \mathrm{~g}$ of carbohydrate (SMFV meal) resulted in a decreased glucose response when compared with the meal without a vegetable dish (SMF meal). It is worth noting that the glucose-lowering effect without an increase in insulin concentrations was observed with a relatively small amount of dietary fibre derived from a vegetable serving that was more realistic than those used in former studies examining dietary fibre ${ }^{(33-36)}$. Thus, the decreased postprandial glucose response after SMFV meal consumption might be attributable not only to a direct effect of the dietary fibre derived from vegetables but also to an effect of the concurrent fat consumption. An earlier study also showed that the addition of $1.7 \mathrm{~g}$ of psyllium alone to pasta did not decrease the postprandial glucose response and that the addition of $1.7 \mathrm{~g}$ of psyllium, $30 \mathrm{~g}$ of fat and $3 \mathrm{~g}$ of sodium propionate to pasta decreased the postprandial glucose response significantly when compared with pasta alone ${ }^{(37)}$. The present results obtained using ordinary food with a small amount of fat and adequate dietary fibre are consistent with those of the prior study.

This is the first study to examine the effect of adding vegetables on the incretin response. Studies on the postprandial incretin response to purified dietary fibre or fibre in grain products have yielded inconsistent results ${ }^{(33-35,37-41)}$. The administration of $\alpha$-glucosidase inhibitors has reportedly been shown to suppress postprandial GIP secretion and enhance postprandial GLP-1 secretion, by shifting the absorption of monosaccharides from the upper small intestine to the lower small intestine ${ }^{(42-44)}$. In the present study, the addition of a vegetable dish of ordinary size to the meal with a moderatefat main dish (SMFV meal) changed neither GIP nor GLP-1 responses when compared with the meal without a vegetable dish (SMF meal). Thus, vegetable intake in ordinary amounts cannot be expected to enhance incretin secretion. In other words, vegetable intake did not lead to a further increase in GIP response, which tends to promote obesity ${ }^{(6)}$.

The present study has limitations. We measured total GIP concentrations, because a commercially available assay for intact GIP was not available at the time of the present study. As dipeptidyl peptidase- 4 activity is reportedly inhibited by some types of peptides ${ }^{(45)}$ and varies depending on nutrients $^{(46)}$, intact GIP concentrations should be measured to reveal the influence of ingesting different meals. We did not examine factors related to gastric emptying, nutrient absorption, insulin receptor activation or glucose utilisation. Therefore, the mechanisms underlying the glucose-lowering effects of side dish co-ingestion observed in the present study could not be determined. Further study is needed to assess the effects of different amounts as well as other types and combinations of foods. However, as no prior study has examined changes in postprandial glucose, insulin, GIP and GLP-1 responses with combinations of dishes generally consumed in ordinary meals, the present study is potentially useful for designing dietary therapy for patients with diabetes. Diets with low glycaemic index and load are considered to be beneficial for improving glycaemic control ${ }^{(1,47)}$. The present results suggest that, from the perspective of clinical management, the consumption patterns and meal content are as important for achieving postprandial glycaemic control as the carbohydrate source consumed with the meal.

In conclusion, the present study was designed to evaluate the effects of consuming recommended amounts of shusai (main dish) and/or fukusai (vegetable side dishes) with boiled white rice (shushoku) in the same meal on postprandial glucose, insulin, GIP and GLP-1 responses. The present results demonstrate the combination of main dishes containing a moderate amount of fat and vegetable dishes with boiled white rice to be beneficial for lowering postprandial glucose concentrations, without excessive increases in insulin and GIP responses, despite the greater energy intake than that with consumption of white rice alone. This finding is potentially useful for clarifying the mechanisms by which recommended combination dishes work in patients with diabetes. 


\section{Acknowledgements}

The authors are grateful to the volunteers for participating in the study. They also thank Yukiko Arai, Makiko Hikichi and Karen Miwa for their help with the test meal loading.

Mayonnaise and frozen vegetables were provided by Kewpie Corporation, Tokyo, Japan. Kewpie Corporation had no role in the design and analysis of the study or in the writing of this article.

The authors' contributions are as follows: N. K. and C. M. designed the study and wrote the article; N. K., C. M., S. M., R. A. and T. M. conducted the study; N. K. performed plasma GIP measurements and conducted the statistical analyses; Y. Y. provided advice on incretin measurements; C. M. had primary responsibility for the final content; all authors read and approved the final manuscript.

None of the authors has any conflicts of interest to declare.

\section{References}

1. International Diabetes Federation (2011) 2011 Guideline for management of postmeal glucose in diabetes. http:// www.idf.org/sites/default/files/postmeal\%20glucose $\% 20$ guidelines.pdf

2. Woerle HJ, Neumann C, Zschau S, et al. (2007) Impact of fasting and postprandial glycemia on overall glycemic control in type 2 diabetes: importance of postprandial glycemia to achieve target HbA1c levels. Diabetes Res Clin Pract 77, $280-285$.

3. Monnier L, Colette C, Dunseath GJ, et al. (2007) The loss of postprandial glycemic control precedes stepwise deterioration of fasting with worsening diabetes. Diabetes Care 30, 263-269.

4. Cavalot F, Pagliarino A, Valle M, et al. (2011) Postprandial blood glucose predicts cardiovascular events and all-cause mortality in type 2 diabetes in a 14-year follow-up: lessons from the San Luigi Gonzaga Diabetes Study. Diabetes Care 34, 2237-2243.

5. Sheard NF, Clark NG, Brand-Miller JC, et al. (2004) Dietary carbohydrate (amount and type) in the prevention and management of diabetes: a statement by the American Diabetes Association. Diabetes Care 27, 2266-2271.

6. Seino Y, Fukushima M \& Yabe D (2010) GIP and GLP-1, the two incretin hormones: similarities and differences. $J$ Diabetes Invest 1, 8-23.

7. Schirra J, Katschinski M, Weidmann C, et al. (1996) Gastric emptying and release of incretin hormones after glucose ingestion in humans. $J$ Clin Invest 97, 92-103.

8. Vollmer K, Holst JJ, Baller B, et al. (2008) Predictors of incretin concentrations in subjects with normal, impaired, and diabetic glucose tolerance. Diabetes 57, 678-687.

9. Pi-Sunyer FX (2002) Glycemic index and disease. Am J Clin Nutr 76, 290S-298S.

10. Papathanasopoulos A \& Camilleri M (2010) Dietary fiber supplements: effects in obesity and metabolic syndrome and relationship to gastrointestinal functions. Gastroenterology 138, 65-72.

11. Japan Diabetes Society (2002) Food Exchange Lists: Dietary Guidance for Persons with Diabetes. Tokyo: Bunkodo.

12. Adachi M (1984) A study on the core-dishes and these combination as a framework of nutrition education on the basis of dish-selecting method. Jpn J Human Ecology 50, 70-107, in Japanese.
13. Hätönen KA, Virtamo J, Eriksson JG, et al. (2011) Protein and fat modify the glycaemic and insulinaemic responses to a mashed potato-based meal. Br J Nutr 106, 248-253.

14. Taniguchi A, Yamanaka-Okumura H, Nishida Y, et al. (2008) Natto and viscous vegetables in a Japanese style meal suppress postprandial glucose and insulin responses. Asia Pac J Clin Nutr 17, 663-668.

15. Ministry of Health, Labour and Welfare, Japan (2009) Dietary Reference Intakes for Japanese 2010. http://www.mhlw. go.jp/shingi/2009/05/s0529-4.html, in Japanese.

16. Krezowski PA, Nuttall FQ, Gannon MC, et al. (1986) The effect of protein ingestion on the metabolic response to oral glucose in normal individuals. Am J Clin Nutr $\mathbf{4 4}$, 847-856.

17. Westphal SA, Gannon MC \& Nuttall FQ (1990) Metabolic response to glucose ingested with various amounts of protein. Am J Clin Nutr 52, 267-272.

18. Nilsson M, Holst JJ \& Björck IM (2007) Metabolic effects of amino acid mixtures and whey protein in healthy subjects: studies using glucose-equivalent drinks. Am J Clin Nutr $\mathbf{8 5}$, 996-1004.

19. van Loon LJ, Saris WH, Verhagen H, et al. (2000) Plasma insulin responses after ingestion of different amino acid or protein mixtures with carbohydrate. Am J Clin Nutr 72, 96-105.

20. Geboes KP, Bammens B, Luypaerts A, et al. (2004) Validation of a new test meal for a protein digestion breath test in humans. J Nutr 134, 806-810.

21. Lan-Pidhainy X \& Wolever TM (2010) The hypoglycemic effect of fat and protein is not attenuated by insulin resistance. Am J Clin Nutr 91, 98-105.

22. Carr RD, Larsen MO, Winzell MS, et al. (2008) Incretin and islet hormonal responses to fat and protein ingestion in healthy men. Am J Physiol Endocrinol Metab 295, E779-E784.

23. Carrel G, Egli L, Tran C, et al. (2011) Contributions of fat and protein to the incretin effect of a mixed meal. Am J Clin Nutr 94, 997-1003.

24. Collier G \& O'Dea K (1983) The effect of coingestion of fat on the glucose, insulin, and gastric inhibitory polypeptide responses to carbohydrate and protein. Am J Clin Nutr 37, 941-944.

25. Collier G, McLean A \& O’Dea K (1984) Effect of co-ingestion of fat on the metabolic responses to slowly and rapidly absorbed carbohydrates. Diabetologia 26, 50-54.

26. Thomsen C, Rasmussen O, Lousen T, et al. (1999) Differential effects of saturated and monounsaturated fatty acids on postprandial lipemia and incretin responses in healthy subjects. Am J Clin Nutr 69, 1135-1143.

27. Maruyama C, Kikuchi N, Masuya Y, et al. (2013) Effects of green-leafy vegetable intake on postprandial glycemic and lipidemic responses and $\alpha$-tocopherol concentration in normal weight and obese men. J Nutr Sci Vitaminol 59, 264-271.

28. Yoder SM, Yang Q, Kindel TL, et al. (2009) Stimulation of incretin secretion by dietary lipid: is it dose dependent? Am J Physiol Gastrointest Liver Physiol 297, G299-G305.

29. Yamane S, Harada N, Hamasaki A, et al. (2012) Effects of glucose and meal ingestion on incretin secretion in Japanese subjects with normal glucose tolerance. J Diabetes Invest $\mathbf{3}$, $80-85$.

30. Robertson MD, Jackson KG, Fielding BA, et al. (2002) Acute ingestion of a meal rich in $n-3$ polyunsaturated fatty acids results in rapid gastric emptying in humans. Am J Clin Nutr 76, 232-238. 
31. Nilsson M, Stenberg M, Frid AH, et al. (2004) Glycemia and insulinemia in healthy subjects after lactose-equivalent meals of milk and other food proteins: the role of plasma amino acids and incretins. Am J Clin Nutr 80, 1246-1253.

32. Jenkins DJ, Goff DV, Leeds AR, et al. (1976) Unabsorbable carbohydrates and diabetes: decreased post-prandial hyperglycaemia. Lancet ii, 172-174.

33. Weickert MO, Mohlig M, Koebnick C, et al. (2005) Impact of cereal fibre on glucose-regulating factors. Diabetologia $\mathbf{4 8}$, 2343-2353.

34. Levitt NS, Vinik AI, Sive AA, et al. (1980) The effect of dietary fiber on glucose and hormone responses to a mixed meal in normal subjects and in diabetic subjects with and without autonomic neuropathy. Diabetes Care 3, 515-519.

35. Morgan LM, Tredger JA, Wright J, et al. (1990) The effect of soluble- and insoluble-fibre supplementation on postprandial glucose tolerance, insulin and gastric inhibitory polypeptide secretion in healthy subjects. Br J Nutr $\mathbf{6 4}$, 103-110.

36. Gustafsson K, Asp NG, Hagander B, et al. (1995) Satiety effects of spinach in mixed meals: comparison with other vegetables. Int J Food Sci Nutr 46, 327-334.

37. Frost GS, Brynes AE, Dhillo WS, et al. (2003) The effects of fiber enrichment of pasta and fat content on gastric emptying, GLP-1, glucose, and insulin responses to a meal. Eur J Clin Nutr 57, 293-298.

38. Juntunen KS, Niskanen LK, Liukkonen KH, et al. (2002) Postprandial glucose, insulin, and incretin responses to grain products in healthy subjects. Am J Clin Nutr 75, 254-262.

39. Raben A, Christensen NJ, Madsen J, et al. (1994) Decreased postprandial thermogenesis and fat oxidation but increased fullness after a high-fiber meal compared with a low-fiber meal. Am J Clin Nutr 59, 1386-1394

40. Willis HJ, Thomas W, Eldridge AL, et al. (2010) Increasing doses of fiber do not influence short-term satiety or food intake and are inconsistently linked to gut hormone levels. Food Nutr Res 54, 5135.

41. Karhunen LJ, Juvonen KR, Flander SM, et al. (2010) A psyllium fiber-enriched meal strongly attenuates postprandial gastrointestinal peptide release in healthy young adults. J Nutr 140, 737-744.

42. Göke B, Fuder H, Wieckhorst G, et al. (1995) Voglibose (AO-128) is an efficient $\alpha$-glucosidase inhibitor and mobilizes the endogenous GLP-1 reserve. Digestion 56, 493-501.

43. Seifarth C, Bergmann J, Holst JJ, et al. (1998) Prolonged and enhanced secretion of glucagon-like peptide 1 (7-36 amide) after oral sucrose due to $\alpha$-glucosidase inhibition (acarbose) in type 2 diabetic patients. Diabet Med 15, 485-491.

44. Lee A, Patrick P, Wishart J, et al. (2002) The effects of miglitol on glucagon-like peptide- 1 secretion and appetite sensations in obese type 2 diabetics. Diabetes Obes Metab 4, 329-335.

45. Tulipano G, Sibilia V, Caroli AM, et al. (2011) Whey proteins as source of dipeptidyl dipeptidase IV (dipeptidyl peptidase-4) inhibitors. Peptides 32, 835-838.

46. Gunnarsson PT, Winzell MS, Deacon CF, et al. (2006) Glucose-induced incretin hormone release and inactivation are differently modulated by oral fat and protein in mice. Endocrinology 147, 3173-3180

47. Bantle JP, Wylie-Rosett J, Albright AL, et al. (2008) Nutrition recommendations and interventions for diabetes: a position statement of the American Diabetes Association. Diabetes Care 31, Suppl. 1, S61-S78. 